\title{
Circulating microRNA-I22a as a diagnostic marker for hepatocellular carcinoma
}

\author{
This article was published in the following Dove Press journal: \\ OncoTargets and Therapy \\ 21 May 2013 \\ Number of times this article has been viewed
}

\author{
Jie Luo' \\ Ming Chen' \\ Hengliu Huang' \\ Tao Yuan ${ }^{2}$ \\ Mingxu Zhang' \\ Kejun Zhang' \\ Shaoli Deng' \\ 'Clinical Laboratory, ${ }^{2}$ Department of \\ Hepatobiliary Surgery, Institute \\ of Surgery Research, Daping Hospital, \\ Third Military Medical University, \\ Chongqing, People's Republic of China
}

Correspondence: Shaoli Deng

Clinical Laboratory, Institute of Surgery Research, Daping Hospital, Third Military Medical University, Chongqing 400042,

People's Republic of China

$\mathrm{Tel}+8602368757602$

Fax +86 023 687I 6530

Email dengs1072@yahoo.com.cn
Background: The purpose of this study was to evaluate the potential value of circulating miRNA-122a and miRNA-221 in the diagnosis of hepatocellular carcinoma.

Methods: Serum samples were obtained from 85 patients with hepatocellular carcinoma and 85 age-matched and sex-matched healthy volunteers. miRNAs were isolated from the serum samples, and alfa-fetoprotein levels were determined. Expression of miRNA-122a and miRNA221 in cases and controls was quantified using U6 sn RNA as the internal control. The diagnostic value of miRNA-122a, miRNA-221, and alfa-fetoprotein was compared by receiver operating characteristic analysis.

Results: The serum miRNA-122a level in patients with hepatocellular carcinoma was significantly reduced in comparison with healthy controls and correlated with known risk factors for hepatocellular carcinoma. Circulating miRNA-221 in patients with hepatocellular carcinoma was higher compared with the control group, but the difference was not statistically significant. Receiver operating characteristic analysis revealed that the diagnostic power of miRNA-122a was suboptimal compared with serum alfa-fetoprotein. Further, the serum alfa-fetoprotein and miRNA-122a combined classifier resulted in performance similar to that of alfa-fetoprotein alone.

Conclusion: The serum miRNA-122a level correlates with risk factors for hepatocellular carcinoma. However, use of miRNA-122a as a diagnostic tool for hepatocellular carcinoma is not superior to alfa-fetoprotein. Further analysis is needed to evaluate the diagnostic power of plasma miRNA-122a for hepatocellular carcinoma.

Keywords: circulating miRNA, miRNA-122a, miRNA-221, hepatocellular carcinoma, alphafetoprotein, molecular diagnostics

\section{Introduction}

Hepatocellular carcinoma (HCC) is the fifth most common malignancy and the third leading cause of cancer mortality worldwide. Each year, there is an incidence of more than 500,000 cases and 600,000 HCC-related deaths. In general, men are more likely to develop HCC than women. The incidence of HCC is highest in regions endemic for hepatitis B virus (HBV), such as People's Republic of China and southeast Asia. ${ }^{1} \mathrm{HCC}$ is highly malignant and deadly, mainly due to the fact that only a small fraction of HCC is operable at the time of diagnosis, when patients are already at an advanced stage of disease and consequently have a very poor prognosis. ${ }^{2}$ Therefore, early detection of HCC is essential for successful treatment and better survival.

Despite the great need for a sensitive and specific early diagnostic marker of HCC, the diagnosis still relies on the serum alpha-fetoprotein (AFP) level coupled with 
diagnostic ultrasound. AFP and ultrasound screening results in both underdiagnosis of a significant number of patients with HCC and a number of false positives in patients with more benign liver disease, such as hepatitis and cirrhosis. ${ }^{3-5}$ Therefore, identifying novel and noninvasive biomarkers to detect HCC with high sensitivity and specificity is a high priority to improve the prognosis and survival in patients with HCC.

MicroRNAs (miRNAs) are approximately 22-nucleotide, noncoding, endogenous RNA molecules with an important role in a number of biological processes, including embryonic development, cell differentiation, and tumorigenesis. ${ }^{6}$ Some miRNAs have been found to have oncogenic or tumor-suppressive properties. ${ }^{7}$ Moreover, miRNA expression profiles can be unique to malignant tissues, and also specific to certain types of cancer. ${ }^{3}$

An HCC-specific miRNA expression profile has been identified and found to distinguish liver tumors from normal liver tissue with high accuracy. ${ }^{4} \mathrm{~A}$ subsequent study found miRNA-221 to be elevated in HCC. ${ }^{8,9}$ Overexpression of miRNA-221 downregulated levels of cyclin-dependent kinase inhibitors, ie, CDKN1B/p27 and CDKN1C/p57, ${ }^{10,11}$ which are related to a poor prognosis in patients with HCC. ${ }^{12,13}$ In addition, expression of miRNA-122a, a liver-specific and the most abundant miRNA in the liver, is repressed in HCC. ${ }^{14,15}$ These decreased miRNA-122a levels are associated with a poor prognosis and metastasis in $\mathrm{HCC},{ }^{16,17}$ which also contributes to the malignant phenotype of HCC cells. ${ }^{18}$ However, these studies analyzed miRNA expression in patient tumor tissues, prompting a need for specific analysis of blood samples.

Given that circulating miRNAs can be used as bloodbased markers for detection of cancer, ${ }^{19}$ we hypothesized that miRNA-122a and miRNA-221 could serve as noninvasive circulating biomarkers for diagnosis of HCC. We investigated miRNA-221 and miRNA-122a expression in serum samples from a group of patients with HCC and controls matched for age and sex. As a control for the diagnostic technique, we also measured AFP levels in the same cohort.

\section{Materials and methods Patient information}

Eighty-five patients being treated for $\mathrm{HCC}$ at the Third Military Medical University Affiliated Daping Hospital from January 2011 to June 2012 were enrolled in the study. In all cases, a pathologist confirmed the clinical diagnosis of HCC. Eighty-five volunteers matched for age and sex were also recruited as controls. All patients and volunteers consented to the study and were investigated for family medical history. The study was reviewed and approved by the medical research ethics committee. Informed consent was obtained from each subject prior to data collection and drawing of blood. A questionnaire was used to collect the data from all study subjects, which included age, sex, family history, tobacco smoking, alcohol consumption, and HBV infection. Information on hepatitis $\mathrm{C}$ virus (HCV) infection was not collected.

\section{Plasma preparation}

First, $2 \mathrm{~mL}$ of peripheral venous blood was collected, supplemented with EDTA to avoid coagulation, and stored at room temperature for no longer than two hours before further processing. To isolate plasma, blood samples were centrifuged at $1200 \times \mathrm{g}$ for 10 minutes at $4^{\circ} \mathrm{C}$. The supernatants were then transferred to $1.5 \mathrm{~mL}$ Eppendorf tubes and centrifuged further at $12,000 \times \mathrm{g}$ and $4^{\circ} \mathrm{C}$ to pellet the cellular components, which were then discarded. The purified plasma samples were transferred to fresh Eppendorf tubes and stored at $-80^{\circ} \mathrm{C}$ for future miRNA extraction.

\section{MiRNA extraction}

Total RNA was extracted from plasma using BioZOL ${ }^{\mathrm{TM}}$ total RNA extraction reagent (Hangzhou Bioer Technology, Hangzhou, People's Republic of China), according to the manufacturer's instructions. The resulting RNA samples were dissolved in $40 \mu \mathrm{L}$ of nuclease-free water and stored at $-80^{\circ} \mathrm{C}$ for future use.

\section{Quantification of plasma miRNA}

Expression of serum miRNA-221 and miRNA-122a was measured using SYBR Green microRNA quantitative reverse transcription polymerase chain reaction reagents (CoWin Biotech Co, Ltd, Beijing, People's Republic of China). Next, $2 \mu \mathrm{L}$ of total RNA was reverse-transcribed at $42^{\circ} \mathrm{C}$ for 30 minutes using miRNA-specific reverse transcription primers. During real-time quantitative PCR reaction, $2 \mu \mathrm{L}$ of reverse transcription products were used as the template. The primers used in the quantitative miRNA PCR were as follows: miRNA221(5'-AGC TAC ATT GTC TGC TGG GTT TC -3'), miRNA-122a (5'-TGG AGT GTG ACA ATG GTG TTT GT-3'), and U6snRNA (5'-CAC CAC GTT TAT ACG CCG GTG-3'). Melting curve analysis was performed at the end of the PCR cycles in order to validate the specificity of the expected PCR product. The PCR reaction was performed in triplicate for the miRNA in each sample. The reaction conditions were as follows: $95^{\circ} \mathrm{C}$ for one minute, 50 cycles at $95^{\circ} \mathrm{C}$ 
for 15 seconds, and $60^{\circ} \mathrm{C}$ for 30 seconds. The $\mathrm{Ct}$ values were determined using SDS2.1 software. The quantitative value for a given sample of miRNA was calculated by subtracting the $\mathrm{Ct}$ value of U6 RNA, which served as the internal reference. The relative expression of specific miRNA was determined by the $\Delta \mathrm{Ct}$ value, which was defined as $\Delta \mathrm{Ct}=(\mathrm{Ct}$ miRNA of sample $\mathrm{x}$ - Ct U6RNA of sample $\mathrm{x}$ ).

\section{Serum AFP detection}

Serum AFP values were determined by AFP chemiluminescence assay using a Beckman i800 luminometer (Beckman Coulter, Chongqing, People's Republic of China). The normal maximum AFP value is $9 \mathrm{ng} / \mathrm{mL}$.

\section{Statistical analysis}

The statistical analysis was performed using Statistical Package for Social Sciences version 15.0 software (SPSS Inc, Chicago, IL). The relative expression of miRNA in our samples demonstrated a normal distribution, so statistically significant differences in miRNA levels between the cases and controls were determined by the independent samples test. Data on the relative expression of miRNA is shown as the mean \pm standard deviation. Comparison of percentages was done using the Pearson Chi-square test or Fisher's Exact test. Diagnostic values for the different classifiers (miRNAs or AFP) were determined by calculating the area under the receiver operating characteristic (ROC) curve. $P<0.05$ was considered to be statistically significant.

\section{Results}

\section{Patient characteristics}

Eighty-five patients diagnosed with HCC as previously reported $^{20}$ were included in this study, and 85 volunteers matched for age, sex, and HBV infection served as controls (Table 1). The AFP level was significantly higher in the HCC group compared with the controls (Table 1). Tumornode-metastasis staging of the HCC patients ${ }^{20}$ is shown in Table 2.

\section{Serum miRNA-22I and miRNA- I22a levels in cases and controls}

MiRNAs were isolated from the peripheral venous blood of patients and controls. miRNA-221 and miRNA-122a levels were quantified using the SYBR Green quantitative reverse transcription PCR assay with U6RNA as the internal control. Consistent with a previous report of miRNA-122 being suppressed in HCC tissue, ${ }^{14}$ we observed a significantly lower miRNA-122a level in serum samples from HCC patients
Table I Clinical and demographic characteristics of patients with hepatocellular carcinoma and healthy controls

\begin{tabular}{|c|c|c|c|c|c|}
\hline \multirow[t]{2}{*}{ Variables } & \multicolumn{2}{|c|}{ Cases $(n=85)$} & \multicolumn{2}{|c|}{ Controls $(n=85)$} & \multirow[t]{2}{*}{$P$-value } \\
\hline & $n$ & $\%$ & $n$ & $\%$ & \\
\hline $\begin{array}{l}\text { Average age } \\
\text { (years) }\end{array}$ & $53.6 \pm 12.0$ & & $50.8 \pm 13.0$ & & $0.154^{a}$ \\
\hline \multicolumn{6}{|l|}{ Sex } \\
\hline Male & 70 & 82.4 & 69 & 81.2 & \\
\hline Female & 15 & 17.6 & 16 & 18.8 & $0.843^{b}$ \\
\hline \multicolumn{6}{|c|}{ Hepatitis B virus } \\
\hline Positive & 75 & 88.2 & 69 & 81.2 & \\
\hline Negative & 10 & 11.8 & 16 & 18.8 & $0.20 \mathrm{I}^{\mathrm{b}}$ \\
\hline \multicolumn{6}{|c|}{ Alfa-fetoprotein } \\
\hline Positive & 67 & 78.8 & I & 1.2 & \\
\hline Negative & 18 & 21.2 & 84 & 98.8 & $<0.00 \mathrm{I}^{\mathrm{c}}$ \\
\hline
\end{tabular}

Notes: 'Independent samples test; 'Pearson Chi-square test; 'Fisher's Exact test.

in comparison with those from controls (Figure 1 and Table 3). We also observed higher miRNA-221 expression in the patient group, but the difference was not statistically significant ( $P=0.225$, data not shown).

\section{Serum miRNA-122a level correlates with multiple risk factors for HCC}

Given that serum miRNA-122a levels were significantly lower in HCC patients, we further analyzed the correlation between serum miRNA-122a level and classic risk factors for HCC. As shown in Table 4, miRNA-122a expression was significantly lower in men with HCC than in women with the disease. A trend of lower miRNA-122a expression was also found in patients who smoked cigarettes, consumed alcohol, had a family history of HCC, or were positive for HBV infection (Table 4). These results show that miRNA-122a expression is associated with known risk factors for HCC.

\section{Diagnostic potential of circulating miRNA-I 22a and AFP in HCC}

We used ROC curves to compare the ability of serum miRNA-122a to discriminate between patients with HCC and controls with that of circulating AFP. Consistent with

Table 2 Clinical staging of patients with hepatocellular carcinoma

\begin{tabular}{ll}
\hline TNM stage & Cases, $\mathbf{n}(\%)$ \\
\hline II & $11(12.9)$ \\
IIIA & $16(18.8)$ \\
IIIB & $19(22.5)$ \\
IVA & $16(18.8)$ \\
IVB & $16(18.8)$ \\
Other* & $7(8.2)$ \\
\hline
\end{tabular}

Note: *Patients without enough medical investigation for staging. Abbreviation: TNM, tumor-node-metastasis. 


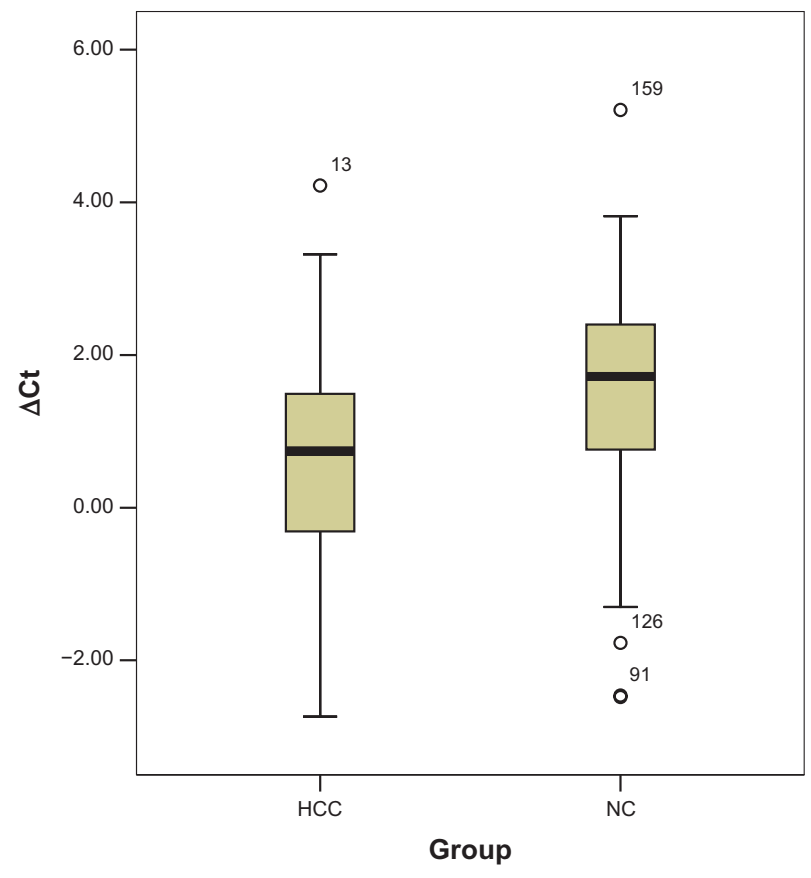

Figure I Relative expression of miRNA-122a in patients with hepatocellular carcinoma and controls.

being the classic $\mathrm{HCC}$ diagnostic marker, AFP showed a very high area under the concentration-time curve (AUC, 0.935), with a cutoff value was $4.69 \mathrm{ng} / \mathrm{mL}$, resulting in a sensitivity of $85.9 \%$ and a specificity of $98.8 \%$ in separating cases and controls. The ROC curve for plasma miRNA-122a expression levels had an AUC of 0.707 , with $70.6 \%$ sensitivity and $67.1 \%$ specificity, respectively, at a cutoff value of 1.205 $(\triangle \mathrm{Ct})$. The ROC curve for the combined classifier (AFP and miRNA-122a) resulted in the highest AUC (0.943) with a sensitivity of $87.1 \%$ and a specificity of $98.8 \%$ (Figure 2 and Table 5), which was significantly better than that of miRNA122a. However, the performance of the combined classifier was not significantly better than AFP alone.

\section{Discussion}

In recent years, miRNAs have emerged as a new class of diagnostic tools for identification of cancer. Because miRNA expression profiles are tissue-specific and differ between malignant and normal tissues, this class of small RNAs may

Table 3 Relative expression of miRNA-22I and miRNA-122a in patients with hepatocellular carcinoma and controls

\begin{tabular}{lccl}
\hline Variables & Cases $(\mathbf{n}=\mathbf{8 5})$ & Controls $(\mathbf{n}=\mathbf{8 5})$ & $\boldsymbol{P}$ value \\
\hline$\Delta \mathrm{Ct}_{\mathrm{t}}(22 \mathrm{I})$ & $-2.10 \pm \mathrm{I} .02$ & $-2.53 \pm \mathrm{I} .43$ & $0.225^{\mathrm{a}}$ \\
$\Delta \mathrm{Ct}(122 \mathrm{a})$ & $0.74 \pm \mathrm{I} .87$ & $1.72 \pm \mathrm{I} .77$ & $<0.00 \mathrm{I}^{\mathrm{b}}$ \\
\hline
\end{tabular}

Notes: alndependent samples test; 'Mann-Whitney $U$ test (median $\pm \mathrm{Q}$, skewed distribution).
Table 4 Correlation between serum miRNA-I22a and known risk factors for $\mathrm{HCC}$

\begin{tabular}{lllll}
\hline HCC risk factors & Group & $\mathbf{n}$ & ${\text { miRNA- } \mathbf{2 2 2} \mathbf{a}^{\mathbf{a}}}$ & $\boldsymbol{P}^{\text {value }}$ \\
\hline Age, years & $40-60$ & 51 & $0.59 \pm 1.33$ & 0.987 \\
& $<40$ or $>60$ & 34 & $0.60 \pm 1.35$ & \\
Sex & Male & 70 & $0.44 \pm 1.34$ & 0.018 \\
& Female & 15 & $1.32 \pm 0.98$ & \\
Smoking status & Ever/current & 35 & $0.30 \pm 1.27$ & 0.083 \\
& Never & 50 & $0.80 \pm 1.34$ & \\
Alcohol & Ever/current & 28 & $0.45 \pm 1.32$ & 0.503 \\
consumption & Never & 57 & $0.66 \pm 1.34$ & \\
Cirrhosis & Yes & 47 & $0.65 \pm 1.25$ & 0.676 \\
& No & 38 & $0.53 \pm 1.43$ & \\
Family history & Yes & 4 & $0.58 \pm 1.28$ & 0.069 \\
of HCC & No & 81 & $0.65 \pm 1.31$ & \\
HBV & Positive & 75 & $0.49 \pm 1.25$ & 0.054 \\
& Negative & 10 & $1.35 \pm 1.70$ & \\
AFP & Positive & 67 & $0.55 \pm 1.28$ & 0.572 \\
& Negative & 18 & $0.75 \pm 1.53$ & \\
\hline
\end{tabular}

Notes: a Mean \pm standard deviation of $\triangle \mathrm{Ct}$ miRNA-122a; bindependent samples test. Abbreviations: AFP, alfa-fetoprotein; HBV, hepatitis B virus; $\mathrm{HCC}$, hepatocellular carcinoma.

be able to serve as a marker to discriminate tumor tissue from normal tissue or for prognostic purposes. ${ }^{21}$ Although several groups have investigated the role of miRNA as a tumor marker in $\mathrm{HCC},{ }^{22-26}$ most of the reports have used histological specimens, and so have limited clinical significance. Given that miRNAs are stable in the circulation, we propose that they may serve as ideal noninvasive biomarkers for diagnosis of HCC. Therefore, we analyzed plasma levels of two miRNAs in patients with HCC and controls, and evaluated their diagnostic performance in the context of AFP, the conventional diagnostic marker of HCC.

Although miRNA-221 levels have been reported to be elevated in HCC tumors, ${ }^{27}$ the difference in serum miRNA-221 levels between patients with $\mathrm{HCC}$ and controls was not statistically significant in our study. Given that miRNA-221 is expressed in organs as well as the liver, ${ }^{28}$ our results suggest that tumor tissue is not the only source of serum miRNA-221. Further studies are needed to investigate the relationship between tumor and serum miRNA-221 levels, and any differences in miRNA-221 levels between different organs to confirm the lack of a diagnostic value of serum miRNA-221 in HCC.

Expression of miRNA-122a is liver-specific and accounts for about $70 \%$ of total miRNA expression in the liver. Recent studies have demonstrated that miRNA-122a expression is decreased during liver tumorigenesis and miRNA-122a can act as a tumor suppressor. Consistent with these findings, we observed a significant decrease in serum miRNA-122a levels in patients with HCC compared with controls. In 


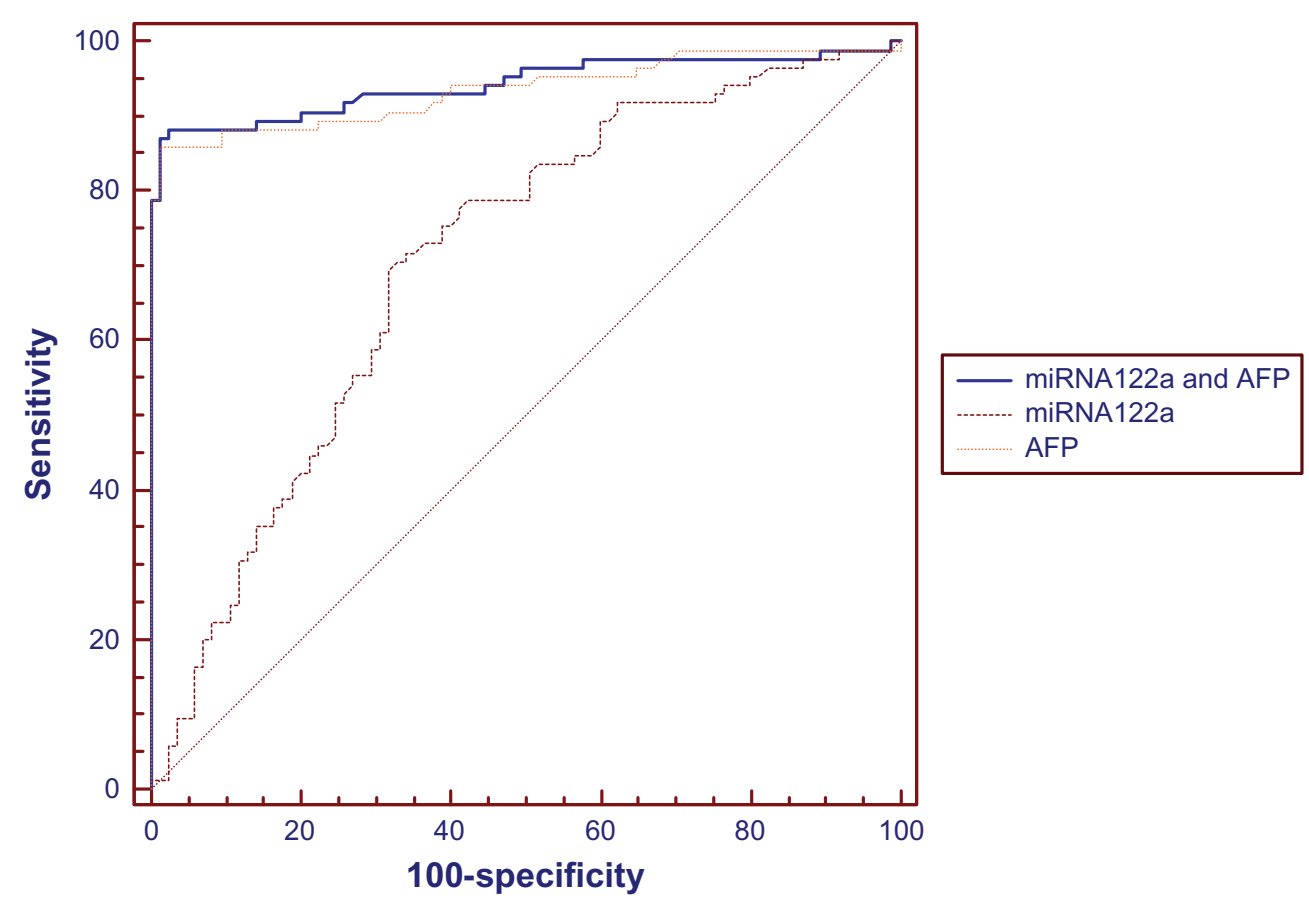

Figure 2 Receiver operating characteristic curves for serum AFP, miRNA-I22a and the combination of AFP and miRNA-122a. Abbreviation: AFP, alfa-fetoprotein.

apparent contrast, $\mathrm{Xu}$ et $\mathrm{al}^{29}$ indicated that serum miRNA122 is elevated in patients with HCC compared with healthy controls. However, the results obtained by $\mathrm{Xu}$ et al and our results are the same, with the only difference being the definition of $\Delta C t$ used. Further, serum miRNA-122a levels in our study were correlated with multiple well known risk factors for HCC, including sex, cigarette smoking, consumption of alcohol, HBV infection, and family history of HCC. All these data strongly suggest that serum miRNA-122a is a promising diagnostic marker for HCC.

Next, we explored the diagnostic potential of miRNA122a by calculating AUC values on the ROC curve for both serum miRNA-122a and AFP. Interestingly, the AUC of AFP $(0.935)$ in our study was much higher than the range previously reported $(0.712-0.830) .{ }^{30-32}$ We reasoned that the high AUC observed in our study was probably due to the fact that most of our patients had late-stage HCC, and therefore had a significantly higher AFP level. The ROC curve for miRNA- 122a gave a promising AUC value of 0.707 , with a sensitivity of $70.6 \%$ and a specificity of $67.1 \%$. Although lower than the AUC for AFP, the diagnostic performance of miRNA-122a in our study is comparable with that of AFP (AUC 0.712-0.830), the AFP immunocomplex (AUC 0.691), squamous cell carcinoma antigen (AUC 0.703), and squamous cell carcinoma immunocomplex (AUC 0.694) from previous studies in patients with HCC. ${ }^{33,34}$ Combining the miRNA-122a classifier with the AFP level, the AUC value was slightly increased compared with AFP alone, suggesting that miRNA-122a may be of some diagnostic value. However, in our study, the diagnostic power of AFP was significantly superior to that of miRNA-122a, and the combined classifier did not result in significantly better performance than AFP alone. These findings establish that serum miRNA-122a has some value as a diagnostic marker, both individually and in combination with AFP. However, AFP levels remain the gold standard for diagnosis of HCC. Further studies on circulating miR122a in

Table 5 Comparison of receiver operating characteristic curves for serum AFP, miRNA-I22a, and the combination of AFP and miRNA-I 22a

\begin{tabular}{llllll}
\hline & AUC & $\mathbf{9 5 \%} \mathbf{C l}$ & Sensitivity (\%) & Specificity (\%) & P value \\
\hline miRNA-I22a and AFP & 0.943 & $0.897-0.973$ & 87.1 & 98.8 & $<0.000 I^{\mathrm{a}}$ \\
miRNA-I22a & 0.707 & $0.632-0.774$ & 70.6 & $67 . I$ & $<0.000 I^{\mathrm{b}}$ \\
AFP & 0.935 & $0.887-0.967$ & 85.9 & 98.8 & $0.4359^{\mathrm{c}}$ \\
\hline
\end{tabular}

Notes: ${ }^{a}$ miRNA- $122 \mathrm{a}$ and AFP $\sim$ miRNA-122a; ${ }^{\mathrm{m}}$ iRNA-122a $\sim$ AFP; ${ }^{\mathrm{c} m i R N A}$ - $122 \mathrm{a}$ and AFP $\sim$ AFP.

Abbreviations: AFP, alfa-fetoprotein; AUC, area under the concentration-time curve; $\mathrm{Cl}$, confidence interval. 
patients with early-stage $\mathrm{HCC}$ will be essential to determine the diagnostic potential of miR122a in liver cancer.

Lanford et $\mathrm{al}^{35}$ found that miRNA-122a was involved in regulating viral replication in $\mathrm{HCV}$-related liver cancer, suggesting that the miRNA-122a expression level may be associated with the rate of $\mathrm{HCV}$ infection. In our study, information on HCV infection was not collected. Unlike in western populations, $\mathrm{HCV}$ infection is not a major risk factor for $\mathrm{HCC}$ in the People's Republic of China. Instead, HBV infection is a more significant risk factor for HCC in the Chinese population. ${ }^{36-39}$ Studies from several groups have demonstrated that endogenous miRNA-122a can inhibit expression of HBV, suggesting a role for miRNA-122a in HBV-related liver cancer. ${ }^{40,41}$ In our study, serum miRNA-122a levels in HBV-positive patients tended to be lower in comparison with those in HBV-negative patients (Table 4). This observation suggests that, in addition to being suppressed by miRNA-122a, HBV may inhibit miRNA-122a expression and presumably increase the risk of $\mathrm{HCC}$ in $\mathrm{HBV}$-positive individuals. We know that people with HBV infection can develop chronic hepatitis, therefore some HBV-positive volunteers may could not be referred to as healthy control but because this study included only 85 controls, and we could not exclude HBV-positive controls or divide them into groups according to the presence or absence of HCC and chronic hepatitis.

In summary, our data suggest that the serum miRNA122a level has some value as a diagnostic tool for HCC. It is possible that serum miRNA-221 levels do not correlate well with miRNA levels in tumor tissue, so miRNA-221 may not be able to serve as a noninvasive diagnostic marker for HCC. In the present study, we included only 85 patients and the same number of matched controls. Future investigations including larger patient populations and patients with earlystage $\mathrm{HCC}$ are needed to confirm the potential diagnostic value of miRNA-122a in HCC.

\section{Disclosure}

Medjaden Bioscience Limited assisted in the preparation of this manuscript. The authors report no other conflicts of interest in this work.

\section{References}

1. Curado MP, Edwards B, Shin HR, et al. Cancer Incidence in Five Continents. Lyon, France: International Agency for Research in Cancer Scientific Publications; 2007. Available from: http://www.iarc.fr/en/ publications/pdfs-online/epi/sp160/CI5vol9-A.pdf. Accessed April 28, 2013.

2. Schwartz M, Roayaie S, Konstadoulakis M. Strategies for the management of hepatocellular carcinoma. Nat Clin Pract Oncol. 2007;4: 424-432.
3. Calin GA, Croce MC. MicroRNA signatures in human cancers. Nat Rev Cancer. 2006;6:857-866.

4. Lu J, Getz G, Miska EA, et al. MicroRNA expression profiles classify human cancers. Nature. 2005;435:834-838.

5. Ladeiro Y, Couchy G, Balabaud C, et al. MicroRNA profiling in hepatocellular tumors is associated with clinical features and oncogene/tumor suppressor gene mutations. Hepatology. 2008;47:1955-1963.

6. Ambros V. The functions of animal microRNAs. Nature. 2004;431: 350-355.

7. Esquela-Kerscher A, Slack FJ. Oncomirs - microRNAs with a role in cancer. Nat Rev Cancer. 2006;6:259-269.

8. Fu X, Wang Q, Chen J, et al. Clinical significance of miRNA-221 and its inverse correlation with p27(Kip1) in hepatocellular carcinoma. Mol Biol Rep. 2011;38:3029-3035.

9. Gramantieri L, Fornari F, Ferracin M, et al. MicroRNA-221 targets Bmf in hepatocellular carcinoma and correlates with tumor multifocality. Clin Cancer Res. 2009;15:5073-5081.

10. Galardi S, Mercatelli N, Giorda E, et al. miRNA-221 and miRNA222 expression affects the proliferation potential of human prostate carcinoma cell lines by targeting p27 Kip1. J Biol Chem. 2007;282: 23716-23724.

11. Fornari F, Gramantieri L, Ferracin M, et al. MiR-221 controls CDKN1C/ p57 and CDKN1B/p27 expression in human hepatocellular carcinoma. Oncogene. 2008;27:5651-5661.

12. Tannapfel A, Grund D, Katalinic A, et al. Decreased expression of p27 protein is associated with advanced tumor stage in hepatocellular carcinoma. Int J Cancer. 2000;89:350-355.

13. Nakai S, Masaki T, Shiratori Y, et al. Expression of p57(KIP2) in hepatocellular carcinoma: relationship between tumor differentiation and patient survival. Int J Oncol. 2002;20:769-775.

14. Kutay H, Bai S, Datta J, et al. Downregulation of miRNA-122 in the rodent and human hepatocellular carcinomas. $J$ Cell Biochem. 2006:99:671-678

15. Chang J, Nicolas E, Marks D, et al. miRNA-122, a mammalian liverspecific microRNA, is processed from hor mRNA and may downregulate the high affinity cationic amino acid transporter CAT-1. RNA Biol. 2004;1:106-113.

16. Fornari F, Gramantieri L, Giovannini C, et al. MiR-122/cyclin G1 interaction modulates $\mathrm{p} 53$ activity and affects doxorubicin sensitivity of human hepatocarcinoma cells. Cancer Res. 2009;69: 5761-5767.

17. Tsai WC, Hsu PW, Lai TC, et al. MicroRNA-122, a tumor suppressor microRNA that regulates intrahepatic metastasis of hepatocellular carcinoma. Hepatology. 2008;49:1571-1582.

18. Bai S, Nasser MW, Wang B, et al. MicroRNA-122 inhibits tumorigenic properties of hepatocellular carcinoma cells and sensitizes these cells to Sorafenib. J Biol Chem. 2009;284:32015-32027.

19. Mitchell PS, Parkin RK, Kroh EM, et al. Circulating microRNAs as stable blood-based markers for cancer detection. Proc Natl Acad Sci U SA. 2008;105:10513-10518.

20. American Cancer Society (ACS). Liver Cancer. 2012. Accessed at http://www.cancer.org/acs/groups/cid/documents/webcontent/003114 -pdf.pdf on January 18, 2013.

21. Garzon R, Calin GA, Croce CM. MicroRNAs in cancer. Аnпи Rev Med. 2009;60;167-179.

22. Chen YT, Kitabayashi N, Zhou XK, Fahey TJ 3rd, Scognamiglio T. MicroRNA analysis as a potential diagnostic tool for papillary thyroid carcinoma. Mod Pathol. 2008;21:1139-1146.

23. Taylor DD, Taylor CG. MicroRNA signatures of tumor-derived exosomes as diagnostic biomarkers of ovarian cancer. Gynecol Oncol. 2008;110:13-21.

24. Liu R, Zhang C, Hu Z, et al. A five-microRNA signature identified from genome-wide serum microRNA expression profiling serves as a fingerprint for gastric cancer diagnosis. Eur J Cancer. 2011;47: 784-791.

25. Iorio MV, Ferracin M, Liu CG, et al. MicroRNA gene expression deregulation in human breast cancer. Cancer Res. 2005;65:7065-7070. 
26. Yanaihara N, Caplen N, Bowman E, et al. Unique micro-RNA molecular profiles in lung cancer diagnosis and prognosis. Cancer Cell. 2006;9:189-198.

27. Rong M, Chen G, Dang Y. Increased MiR-221 expression in hepatocellular carcinoma tissues and its role in enhancing cell growth and inhibiting apoptosis in vitro. BMC Cancer. 2013;13:21.

28. Yang QE, Racicot KE, Kaucher AV, Oatley MJ, Oatley JM. MicroRNAs 221 and 222 regulate the undifferentiated state in mammalian male germ cells. Development. 2013;140:280-290.

29. Xu J, Wu C, Che X, et al. Circulating microRNAs, miRNA-21, miRNA122, and miRNA-223, in patients with hepatocellular carcinoma or chronic hepatitis. Mol Carcinog. 2011;50:136-142.

30. Porta C, De Amici M, Quaglini S, et al. Circulating interleukin-6 as a tumor marker for hepatocellular carcinoma. Ann Oncol. 2008;19: 353-358.

31. Mao Y, Yang H, Xu H, et al. Golgi protein 73 (GOLPH2) is a valuable serum marker for hepatocellular carcinoma. Gut. 2010;59: 1687-1693.

32. Shen Q, Fan J, Yang XR, et al. Serum DKK1 as a protein biomarker for the diagnosis of hepatocellular carcinoma: a large-scale, multicentre study. Lancet Oncol. 2012;13:817-826.

33. Giannelli G, Marinosci F, Trerotoli P, et al. SCCA antigen combined with alpha-fetoprotein as serologic markers of HCC. Int J Cancer. 2005;117: 506-509.
34. Giannelli G, Fransvea E, Trerotoli P, et al. Clinical validation of combined serological biomarkers for improved hepatocellular carcinoma diagnosis in 961 patients. Clin Chim Acta. 2007;383:147-152.

35. Lanford RE, Hildebrandt-Eriksen ES, Petri A, et al. Therapeutic silencing of microRNA-122 in primates with chronic hepatitis c virus infection. Science. 2010;327:198-201.

36. Kaplan DE, Reddy KR. Rising incidence of hepatocellular carcinoma: the role of hepatitis $\mathrm{B}$ and $\mathrm{C}$; the impact on transplantation and outcomes. Clin Liver Dis. 2003;7:683-714.

37. El-Serag HB. Hepatocellular carcinoma: an epidemiologic view. J Clin Gastroenterol. 2002;35:S72-S78.

38. El-Serag HB, Davila JA, Petersen NJ, McGlynn KA. The continuing increase in the incidence of hepatocellular carcinoma in the United States: an update. Ann Intern Med. 2003;139:128.

39. Di Bisceglie AM, Lyra AC, Schwartz M, Reddy RK, Martin P, Gores G. Hepatitis C-related carcinoma in the United States: influence of ethnic status. Am J Gastroenterol. 2003;98:2060-2063.

40. Qiu LP, Fan HX, Jin WS, et al. MiR-122-induced downregulation of HO-1 negatively affects miRNA-122-mediated suppression of HBV. Biochem Biophys Res Commun. 2010;398:771-777.

41. Fan G, Wang CM, Tian C, et al. MiR-122 inhibits viral replication and cell proliferation in hepatitis B virus-related hepatocellular carcinoma and targets NDRG3. Oncol Rep. 2011;26:1281-1286.
OncoTargets and Therapy

\section{Publish your work in this journal}

OncoTargets and Therapy is an international, peer-reviewed, open access journal focusing on the pathological basis of all cancers, potential targets for therapy and treatment protocols employed to improve the management of cancer patients. The journal also focuses on the impact of management programs and new therapeutic agents and protocols on

\section{Dovepress}

patient perspectives such as quality of life, adherence and satisfaction. The manuscript management system is completely online and includes a very quick and fair peer-review system, which is all easy to use. Visit http://www.dovepress.com/testimonials.php to read real quotes from published authors. 